7. Reprod. Fert. (1966) 11, 161-163

BRIEF COMMUNICATION

\title{
A DIRECT METHOD FOR THE DISPLAY OF CHROMOSOMES FROM EARLY PIG EMBRYOS
}

\author{
RICHARD A. MaFEELY \\ Department of Clinical Studies, School of Veterinary Medicine, \\ University of Pennsylvania, Philadelphia, Pennsylvania
}

(Received 29th September 1965)

The demonstration of chromosome abnormalities associated with spontaneous abortions in humans (Carr, 1963) has prompted the investigation of chromosomes from embryos of other mammalian species. This communication describes a method for the demonstration of chromosomes from early pig embryos.

A gilt is mated on the 1st day of oestrus and again on the following day, if she will accept the boar. On the 10th day after the original mating, the pig is slaughtered and the cervix, uterus, oviducts and ovaries are removed as a unit. The number of corpora lutea are counted and used as the criterion for the number of ova produced (Perry \& Rowlands, 1962). Ten gilts were studied with this collection technique. A total of 106 corpora lutea were observed, and ninety-eight blastocysts were collected $(92.5 \%)$ which compares favourably with $95.5 \%$ reported by Perry \& Rowlands (1962). The mesometrium is cut away, and the coiled uterine horns extended. The uterus is suspended vertically by the cervix, and a funnel is introduced through the cervical canal into the cavity of the uterus. The uterine horns are bisected at the junction of the Fallopian tube and 150 to $200 \mathrm{ml}$ of Eagle's medium with $15 \%$ foetal calf serum are poured through the funnel and collected in a beaker at the tubal extremities of the suspended uterus. The blastocysts, which are flushed out in the process, are visible macroscopically in the fluid. It is usually possible to collect all of the blastocysts with one or two flushings of each horn. The time at which pregnancy is interrupted is important. It has been found that after 10 days the blastocysts elongate quite rapidly and, when flushed from the uterus, become entangled. $\mathrm{Up}$ to 10 days, the blastocysts are quite small and may be barely visible to the naked eye. The number of cells in these blastocysts is generally too small to produce satisfactory results with this technique.

Each blastocyst is transferred from the flushing fluid to a vial containing $5 \mathrm{ml}$ of Eagle's medium with $15 \%$ foetal calf serum $+0.25 \mu \mathrm{g}$ of Colcemide (Ciba) with a pasteur pipette and incubated for $1 \mathrm{hr}$ at $37^{\circ} \mathrm{C}$. It is necessary throughout the procedure to use siliconized glassware to prevent the cells from sticking to the glass. Separate pipettes should be used for each blastocyst to avoid cross contamination of cells. Although it is possible to obtain adequate 
chromosome preparations without this step, the Colcemide produces some contraction of the chromosomes and separation of the chromatids, which are desirable when karyotype analysis is to be performed. The blastocysts are then transferred to another vial containing $5 \mathrm{ml}$ of a hypotonic solution at $37^{\circ} \mathrm{G}$ consisting of 1 part calf serum to 5 parts distilled water. After $12 \mathrm{~min}$, the blastocysts are transferred to a $1 \mathrm{ml}$ siliconized centrifuge tube containing 1 part glacial acetic acid to 3 parts absolute methyl alcohol. Care must be taken to transfer as little of the hypotonic solution to the fixative as possible. After 15 min fixation, the blastocyst is broken up by gentle agitation with a pasteur pipette and then allowed to fix for an additional $15 \mathrm{~min}$. The tubes are then centrifuged at 1000 to $1500 \mathrm{rev} / \mathrm{min}$ for $5 \mathrm{~min}$, when the supernatant is carefully aspirated and replaced by fresh fixative. The cell 'button' is resuspended by gentle pipetting, and the cells allowed to fix for 10 additional minutes. The fixative is changed twice more in a similar manner, and the cells are finally resuspended in one or two drops of fresh fixative. A drop of the cell suspension is placed on a clean, wet slide and the alcohol ignited by rapidly passing the slide through the flame from a bunsen burner. When the slides are thoroughly dry, they are stained with Giemsa stain and examined microscopically. Wellspread metaphase plates can be photographed for detailed analysis.

The method described usually provides sufficient dividing cells for chromosome analysis. In some cases many of the spreads are only suitable for counting chromosomes, but there are almost always several figures which can be accurately karyotyped.

The advantages of a direct method of preparation over techniques utilizing tissue culture are: (1) the technique is quicker and easier, (2) strict asepsis in obtaining and handling the blastocysts is not required, and (3) cells with abnormal chromosome complements are not discriminated against as they might be under culture conditions, and a true ratio of normal to abnormal dividing cells is obtained.

It is apparent from our preliminary studies, and those of Bomsel-Helmreich (1961), that chromosome aberrations do exist in early pig embryos. One Yorkshire gilt, from which eight blastocysts were recovered, possessed eight corpora lutea. Chromosome analysis of these blastocysts revealed that seven of them possessed the diploid number of chromosomes. In the eighth blastocyst, all but two of the cells were triploid. The other two cells were in the hexaploid range. In a blastocyst from another Yorkshire gilt, an apparent deletion of part of a chromosome in the D group was observed (Plate 1). Of the eleven cells suitable for analysis, all possessed the normal diploid number of chromosomes. The aberration was positively identified in nine of these cells while in two the identification was equivocal. More extensive studies on the incidence of chromosome anomalies in 10-day pig embryos are currently being conducted and will be reported in more detail at a later date.

I wish to thank Dr W. G. D. Hare and Dr J. D. Biggers for their invaluable suggestions. This work was supported by a post-doctoral fellowship from the National Institute of Child Health and Human Development and USPHS Grants-FR-00120 and 5TI CA5097. 
PLATE 1

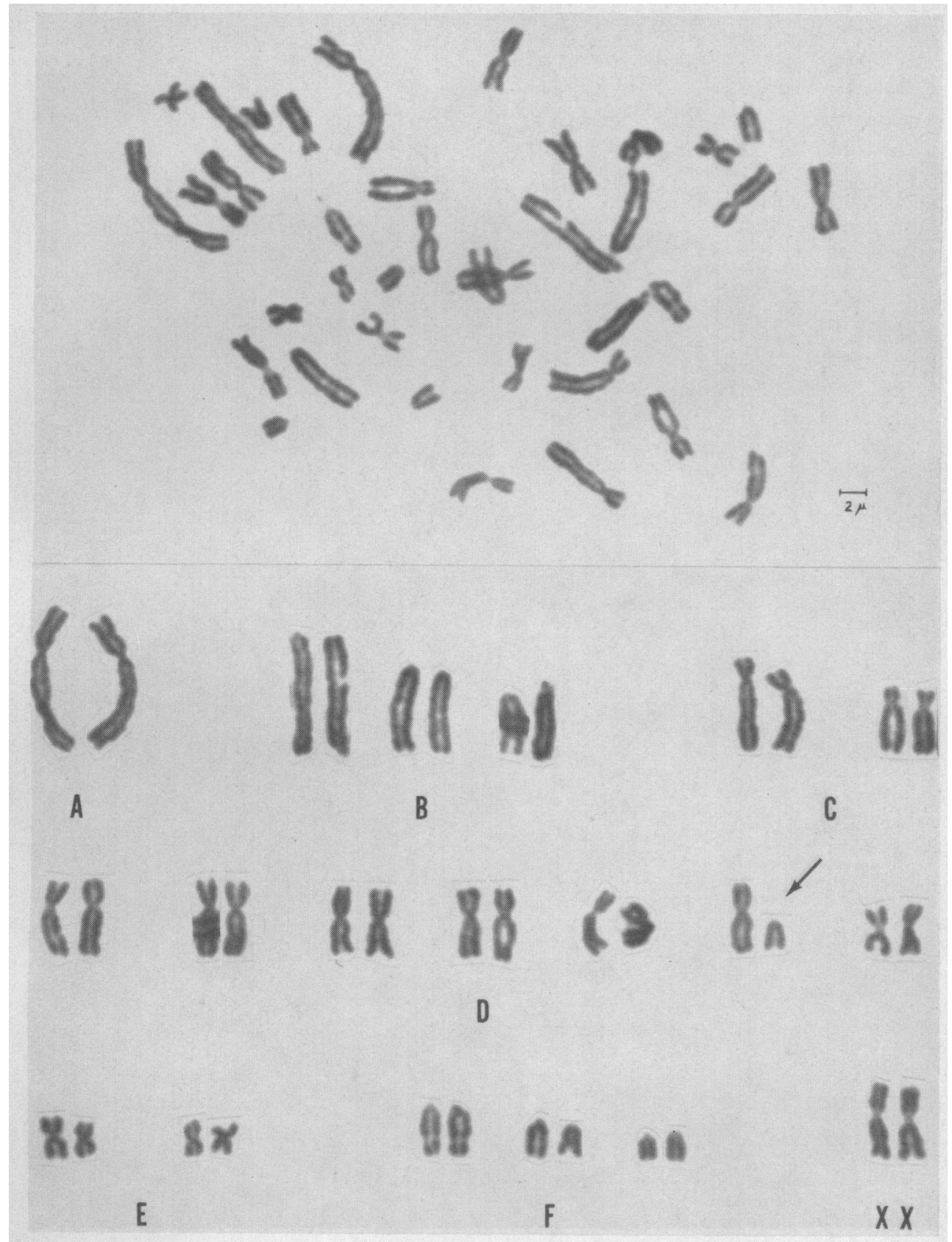

Karyotype from a pig blastocyst showing an apparent deletion of one chromosome.

(Facing p. 162) 


\section{REFERENGES}

Bomsel-Helmreich, O. (1961) Hétéroploide expérimentale chez la Truie. Proc. IVth int. Congr. Anim. Reprod., The Hague, 3, 578.

CARR, D. H. (1963) Chromosome studies in abortuses and stillborn infants. Lancet, ii, 603.

Perry, J. S. \& Rowlands, I. W. (1962) Early pregnancy in the pig. F. Reprod. Fert. 4, 175. 